\title{
CORRIGENDUM
}

\section{MIDDLE EIGHT - Are workers musicians?}

\section{SIMON FRITH}

Popular Music regrets to announce that there has been an error in the title of the above paper. The correct title of this article is provided below.

MIDDLE EIGHT- Are musicians workers?

\section{Reference}

Frith, S. 2016. 'MIDDLE EIGHT - Are workers musicians?', Popular Music, 36, 111-15, doi: 10.1017/ S0261143016000714. 